\title{
Amyand's Hernia in Forensic Autopsy: Case Report and Review of the Literature
}

\author{
Nursel Türkmen ${ }^{1}$, Bülent Eren², Halis Dokgöz ${ }^{3}$ \\ Uludağ University Medical Faculty, Forensic Medicine Department, Council of Forensic \\ Medicine of Turkey, Bursa Morgue Department, Bursa, Turkey ${ }^{1}$ \\ Council of Forensic Medicine of Turkey, Bursa Morgue Department, Bursa, Turkey² \\ Mersin University Medical Faculty, Forensic Medicine Department, Mersin, Turkey ${ }^{3}$
}

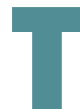

he presence of vermiform appendix in inguinal hernia is rare and is known as Amyand's hernia. Reported case was 73 years old man admitted to the hospital with chest pain who dead soon after admittance in the emergency department of the university hospital. In the macroscopic autopsy investigation, after opening the hernial sac, the vermiform appendix and caecum were detected free, without adhesions in the hernial sac. Death was reported due to acute myocardial infarction. Investigation of this rare entity in forensic autopsy is important for scientific classification, description and also correct pre-postoperative management and appropriate surgery. Key words: Amyand's Hernia, Forensic Autopsy.

Corresponding author: Bülent Eren, MD. Council of Forensic Medicine of Turkey, Bursa Morgue Department, Heykel, Osmangazi 16010, Bursa, Turkey. Tel: +90 22422203 47. Fax:+090 224225 51 70. E-mail:drbulenteren@gmail.com.

\section{INTRODUCTION}

Acute appendicitis in an inguinal hernia sac was referred as Amyand's hernia to honour Claudius Amyand, who was the first who described the presence of a perforated appendix within the inguinal hernial sac in 1735(1-7). Investigation of anatomic and pathological features of this rare entity in forensic autopsy is important determinants for scientific classification, description also correct pre-postoperative managements and appropriate surgery.

\section{CASE REPORT}

Reported case of Amyand's hernia is male aged 73 years, where the appendix was found in a right inguinal hernia during forensic autopsy. The medical history of the patient included arterial hypertension history with medical treatment. The victim was admitted to the hospital with chest pain who dead soon after admittance in the emergency department of the university hospital. The death was considered to be suspicious by prosecutor and an autopsy was mandated. Gross external examination detected swelling in the right inguinal region (Figure 1). In the macroscopic autopsy investigation, the deep facia, the external oblique aponeurosis and the spermatic cord were identified after opening the hernial sac; the vermiform appendix and caecum were detected free, without adhesions in the hernial sac (Figure 2). In the macroscopic investigation; the appendix was $11 \mathrm{~cm}$ in length with a maximum diameter of

$0.7 \mathrm{~cm}$. Histological in- Figure 1 External apperance vestigation did not reveal any pathological findings of the appendix vermiformis. Analysis of the organ specimens revealed none of the substances screened for in systematic toxicological methods. Macroscopic examination of brain, both lungs showed edema and congestion. Histological examination of the heart revealed findings corresponding acute myocardial infarction. Death was reported due to acute myocardial infarction.

\section{DISCUSSION}

Amyand's hernia is a rare hernia in which an incarcerated or perforated appendix is found in the right inguinal canal (1-7). The presence of having a normal appendix within the hernial sac is a rare disease, reported in $1 \%$ of cases of inguinal hernia repair. The appendix can be complicated by acute appendici-

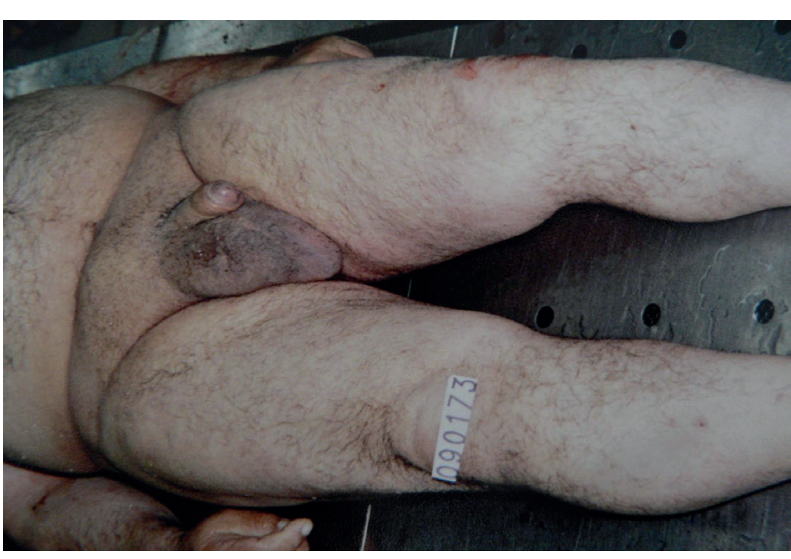


tis in $0.13 \%$ of cases. Often, it requires an emergent surgical treatment (4), this condition is unusual in neonates and in infants $(2,3,5)$. However, one case of a threemonth old boy has been reported in which a right sided sliding appendiceal inguinal hernia was diagnosed preoperatively with sonography (7).This disease is often very difficult to diagnose, and

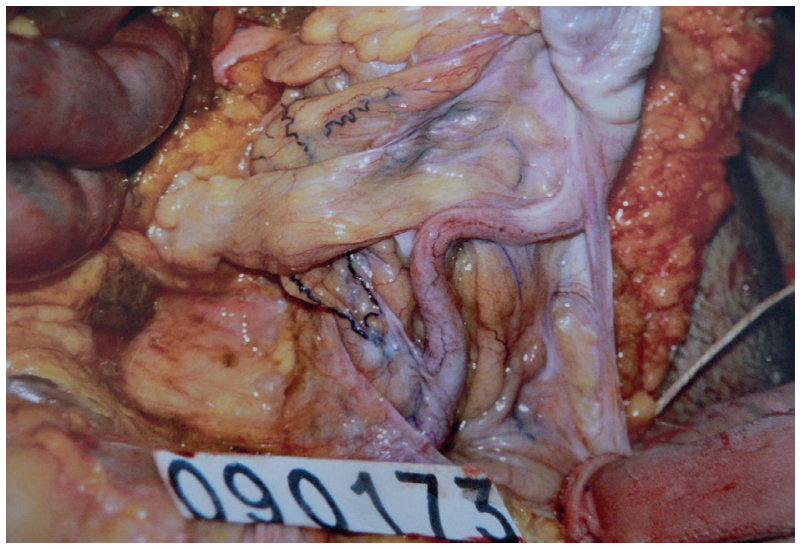

Figure 2 Vermiform appendix and caecum at the opening of the sac of the inguinal hernia.

are not well described in the literature. We report a case of Amyand's hernia, which was correctly diagnosed by CT in a female patient presented to the emergency department with right lower quadrant pain and clinical suspicion of a strangulated omentocele (8). The occurrence of herniated appendices is mostly reported in a right inguinal hernial sac, probably as a consequence of the normal anatomical position (9), extensive literature search revealed three reported cases of left sided Amyand's hernia $(10,11,12)$. Amyand's hernia is different entity for the surgeon. The recommend surgical procedure is laparoscopic appendectomy and open repair of the inguinal hernia without using mesh (1).The presence of the appendix in an inguinal hernial sac, referred to as "Amyand's hernia", is an uncommon, interesting entity

\section{REFERENCES}

1. Milanchi S, Allins AD.Amyand's hernia: history, imaging, and management.Hernia. 2008; 12: 321-322.

2. Logan MT, Nottingham JM. Amyand's hernia: a case report of an incarcerated and perforated appendix within an inguinal hernia and review of the literature. Am Surg. 2001; 67: 628-629.

3. Thomas WE, Vowles KD, Williamson RC. Appendicitis in external herniae. Ann R Coll Surg Engl. 1982; 64: 121-122.

4. Nigri G, Costa G, Valabrega S, Aurello P, D’Angelo F, Bellagamba R, Lauro A, Ramacciato G. A rare presentation of Amyand's hernia. Case report and review of the literature. Minerva Chir. 2008; 63: 169-174.

5. Baldassarre E, Centonze A, Mazzei A, Rubino R. Amyand's hernia in premature twins. Hernia. 2009; 13: 229-230.

6. Tisdale JB, Barwell NJ. Amyand's hernia and peri-appendicular abscess in primary care. Hernia. 2008; 12: 311-312.

7. Celik A, Ergun O, Ozbek SS, Dokumcu Z, Balik E. Sliding appendiceal inguinal hernia: preoperative sonographic diagnosis. J Clin Ultrasound. 2003; 31: 156-158.

8. Ash L, Hatem S, Ramirez GA, Veniero I. Amyand's hernia: a case report of prospective CT diagnosis in the emergency department. Emerg Radiol. 2005; 11: 231232.

9. Pellegrino JM, Feldman SD. Case report: acute appendicitis in an inguinal hernia. N J Med. 1992; 89: 225-226.

10. Gupta S, Sharma R, Kaushik R. Left-sided Amyand's hernia. Singapore Med J. 2005; 46: 424-425.

11. Breitenstein S, Eisenbach C, Wille G, Decurtins $M$. Incarcerated vermiform appendix in a left-sided inguinal hernia. Hernia. 2005; 9: 100-102.

12. Carey LC. Acute appendicitis occurring in hernias: a report of 10 cases. Surgery. 1967; 61: 236-238. 